\title{
Parallel Trade in Pharmaceuticals: The Impact on Welfare and Innovation
}

\author{
Richard P. Rozek and Richard T. Rapp* \\ National Economic Research Associates, Inc.
}

\begin{abstract}
Differences among nations in political, social, economic, legal and regulatory regimes cause differences in prices across countries, which, in turn, create opportunities for arbitrage or 'parallel trade.' As with any form of arbitrage, one effect of parallel trade is to diminish the price differentials that gave rise to the arbitrage opportunity. At least four market situations exist in which parallel trade may reduce welfare and weaken the intellectual property rights of innovators. In these settings, a policy that restricts either parallel trade or incentives for parallel trade yields net economic benefit to society. This paper summarizes these situations.
\end{abstract}

\section{Introduction}

Differences among nations in political, social, economic, legal and regulatory regimes cause differences in prices across countries which, in turn, create opportunities for arbitrage or parallel trade. Typically a parallel trader obtains a product in a low-price country and ships it to a high-price country for resale to compete with products sold through authorized distributors in the high-price country. As with any form of arbitrage, one effect of parallel trade is to diminish the price differentials that gave rise to the arbitrage opportunity.

Various economic and political pressures, if unopposed, tend to foster parallel

* National Economic Research Associates, Inc, 1800 M street, N.W. Washington, D.C. 20036, U.S.A. We gratefully acknowledge research support from the Pharmaceutical Manufacturers Association. We also thank an anonymous referee for helpful comments regarding the organization of this paper. 
trade. There are, however, at least four market situations in which parallel imports may reduce welfare and weaken the intellectual property rights of innovators. In these settings, a policy that restricts parallel trade yields a net economic benefit to society. The settings are:

- In cases where price discrimination (also known as differential pricing) is welfare enhancing - such as when it facilitates entry into new markets and, thus, expands output - parallel imports inhibit society from achieving the welfare gains.

- If free-rider problems exist, parallel importers will undercut efficiency-enhancing information and service activities by the authorized distributors in a country. As a result, costs will rise, competition will suffer and consumers will be worse off.

- In situations where monopsony power creates pricing distortions, parallel imports will decrease the ability of sellers to minimize the effects of the distortions.

- For technology dependent industries, parallel imports weaken intellectual property protection, with a consequent adverse impact on the incentive for firms to devote resources to research and development $(R \& D)$. In the long run, consumers will have access to fewer new, improved products.

In this paper, we discuss the four welfare-enhancing aspects of restricting parallel imports in more detail, with a special focus on the pharmaceutical industry since it exhibits all four of these characteristics. See Sections II through V, respectively. We summarize our conclusions in Section VI.

Much work on understanding the effects of parallel trade in pharmaceuticals remains. The benefits and costs we discuss in this paper have yet to be quantified. We rely upon our understanding of the relative orders of magnitude of the effects of parallel trade. The research agenda on this important policy issue should include more precise estimation of the effects of parallel trade and inquiry into factors that determine the optimal size of an efficient distribution area.

\section{Differential Pricing}

\section{A. Background}

Countries differ from one another in a number of ways such as with respect to per capita income, consumption patterns, government regulation, taxes, inflation rates, and trade barriers. As a result, the seller of a product available worldwide may set different prices across countries, which are not explained by differences in ex- 
change rates, transport costs or other cost related variables. For such price differences to persist, (i) the seller of the product must have some control over the price; (ii) countries must have different sensitivities of demand to changes in price; and (iii) there must be no opportunity for arbitrage or resale of the product obtained in the low-price countries to consumers in the high-price countries.

Three types of differential pricing or price discrimination are generally discussed in the economics literature. Under first degree price discrimination each consumer pays the maximum he is willing to pay for a product. The seller extracts all the consumers' surplus. Second degree price discrimination is similar to first degree except that the seller divides consumers into distinct classes rather than treating each consumer separately. The seller, facing a single demand curve in this case, partitions demand into blocks. Under third degree price discrimination, the seller divides customers into two or more independent groups each with its own demand relationship.

Of the three conditions cited above for differential pricing to be feasible, the last condition is the one clearly subject to the direct influence of parallel imports. As countries continue to dismantle trade barriers, the opportunities to engage in arbitrage activities will increase since the cost of engaging in parallel trading activity will decrease. Thus, the magnitude of the difference in price that makes parallel trade profitable will decrease as well. If no other policy changes occur, parallel imports will tend to reduce or eliminate intercountry price differences. This may not necessarily be in the public interest in either the short run or long run.

The Robinson-Patman Act has dominated the legal framework for assessing price discrimination in the U.S. since 1936. To an economist, price discrimination simply means either charging two distinct prices for an identical product when the price differences are not explained by differences in cost or charging the same price to two buyers when the costs of serving those buyers differ. The Act addresses only the former as price discrimination. Because of the legal provisions against price discrimination in the U.S. (and Europe), it has taken on a pejorative tone - akin to race discrimination - rather than retaining the more appropriate value-neutral definition. For this reason, we use the term differential pricing as a synonym for price discrimination.

Indeed, the universality of differential pricing leads economists to conclude generally that it is an inevitable feature of healthy economies in markets in which less than perfect competition prevails. Under the Robinson-Patman Act, on the 
other hand, price differences alone constitute price discrimination. In practice, the Act stifles competition by inhibiting the free movement of prices in markets. Manufacturers use the Act to justify competitive weaknesses, claiming to buyers that the Act prevents them from cutting price. The Act may actually facilitate price fixing, a practice the Sherman Act is designed to prevent, and forcibly and inefficiently shift competition to nonprice terms.

\section{B. Output Expansion and Welfare}

Differential pricing benefits a seller that has some control over price by allowing the seller to charge a price closer to consumers' willingness to pay. When the seller is able to separate classes of consumers with different sensitivities of demand to price changes and is able to prohibit resale from one class to another, it can charge each class an appropriate price and, thereby, increase its profit. Specifically, the seller will charge a high price to the class of consumers who are most insensitive to price and progressively lower prices to those classes of consumers who are progressively more sensitive to price. The ultimate issue is whether consumers win or lose from differential pricing. Generally speaking, an increase in output is a necessary, but not a sufficient, condition for an increase in welfare (defined as the sum of consumers' and producers' surpluses) from differential pricing. That is, unless output increases, differential pricing yields a welfare loss. If the low-price market would have gone unserved without differential pricing, the output-expanding effect is obviously beneficial. However, when no new markets are served as a result of differential pricing, output may not expand and there may be no welfare gain. Since output expansion is not a sufficient condition for differential pricing to increase welfare, economists analyze the effects of differential pricing on a case-by-case basis. See Schmalensee [1981] and Varian [1987].

Markets include both product and geographic dimensions. For our discussion of parallel imports, we limit our focus to the geographic dimension; that is, whether there are benefits from preserving price differences for products across countries.

Geographic price differentials create opportunities for parallel trade; that is, purchasing a product in the low-price country and reselling in the high-price country, undercutting the price in the high-price country. The existence of parallel imports will tend to result in a uniform price across countries. This is not necessarily welfare enhancing. Consider a pharmaceutical product that is distributed in both 
developed and developing countries. In the developing country, the manufacturer may charge lower prices, albeit in excess of incremental production costs, for pharmaceutical products because of factors such as income or local patent piracy. The level of sales in the developing country is too small typically to affect the level of R\&D by pharmaceutical manufacturers. ${ }^{1}$ However, reselling by parallel importers reduces the ability of an innovative manufacturer to earn a return on its $R \& D$ investment in the developed country. Innovative manufacturers may ultimately decide to withhold their products from developing countries in order to maintain prices in the developed country. If the manufacturer actually forgoes the opportunity to achieve lower costs of production due to scale or learning economies, prices in the developed country will be even higher. The timely recovery of investment in $R \& D$ propels additional research. Consumers in the developing country have access to the product. Meanwhile, consumers in the developed country have access to the product, at prices that capture the scale and learning economies, which would not be realized absent sales in the developing country.

This example illustrates three types of adverse effects from allowing parallel imports of pharmaceutical products and other products that require similar substantial investments in $R \& D$ prior to marketing. First, parallel trade from a low-price country to a high-price country undermines the intellectual property protection in the high-price country and, thus, the incentive for innovative manufacturers to devote resources to R\&D. Second, with parallel imports from the low-price country, manufacturers will have an incentive to withhold existing products and not introduce new products into that country. Thus, consumers in the low-price country will lose access to valuable therapies. Finally, consumers in the low-price country will pay higher prices and innovative manufacturers will earn lower profits if parallel trade interferes with the realization of scale and learning effects through additional sales in the developing country. The result is that consumers in both the low- and highprice countries, as well as the manufacturer, will be worse off.

Generally, pharmaceutical sellers face different degrees of price sensitivity across countries due to such factors as differences in income, age or health status of the population, or laws governing the industry. Charging a uniform price may mean that some markets will not be served if, for example, lower priced substitutes are available. This means that both the total output of the patented product and welfare

1. This view may not be confined to developing countries. 
may be lower. In addition, if declining marginal costs from scale or learning economies exist and differential pricing opens new markets, welfare gains are possible.

We have considered two measures of welfare: whether the sum of consumers' and producers' surpluses increases and whether every economic agent is better off - or at least no worse off - under the policy change. The latter standard is much stronger than the first. Unfortunately, it is impossible with any degree of generality to predict the consequences of permitting or restricting parallel imports unambiguously on economic welfare by either measure. As Hausman and Mackie-Mason [1988] discuss, the opportunity created by differential pricing to serve new markets increases the likelihood of a welfare gain of both types. If differential pricing permits a firm to serve only one additional market and its marginal cost is either constant or decreasing, then a welfare gain of the second type can be realized. However, if a firm serves more than one market under uniform pricing, it cannot realize a welfare gain of the second type by serving new markets, even though a welfare gain of the first type is possible under differential pricing. Finally, if no new markets open as a result of differential pricing, a firm may realize a welfare gain of the second type when the price in each market is lower than the uniform price.

In summary, restricting parallel imports helps firms to maintain differential prices. Differential pricing is a mechanism by which some sellers can serve new markets (e.g., developing countries) and possibly exploit scale and learning effects. The pharmaceutical industry appears to be one example where it is possible to achieve these effects. Therefore, restricting parallel imports of pharmaceuticals is likely to enhance welfare.

\section{High Cost of R\&D}

Even if neither type of welfare gain is possible, there are benefits from differential pricing in terms of future innovative activities. The high costs of conducting R\&D for new pharmaceutical products creates a situation in which the marginal cost of producing additional units of a product is less than the average total cost of the product. DiMasi et. al. [1991] estimate the cost to develop a new pharmaceutical product is $\$ 231$ million. Consider a firm that pays $\$ 231$ million as an entry fee into the market and then produces the product at a constant per unit cost of production. In other words, let $\mathrm{R}=\$ 231$ million and assume the firm can produce at 
a constant marginal cost $c$. In such a situation, the average total cost function is dominated by the high cost of R\&D. As quantity produced increases, the average total cost decreases. Suppose a pharmaceutical firm can sell its product in a lowprice country at a price $p$ that exceeds the marginal cost of production, but is less than average total cost, and at a price $p^{*}$ in a high-price country where $p^{*}$ exceeds average total cost. The losses (relative to average cost) in the low-price country are offset by profits in the high-price country. If the price in the high-price country drops below average total cost, as would typically be the case with parallel imports, the firm cannot continue operating in the long run. Alternatively, the firm may withdraw from the low-price country to the detriment of the manufacturer and the consumers in both the high- and low-price countries.

\section{Control of Distribution}

A second way to approach the analysis of parallel trade is to view the national borders as simply the boundaries of the exclusive territories that manufacturers impose upon their own distribution systems. Exclusive territories of this sort are an important example of a class of interfirm arrangements known as nonprice vertical restraints.

\section{A. Background}

Understanding the evolution of economic analysis and public policy on nonprice vertical restraints is important to the debate on parallel imports for two reasons: first, it demonstrates that expected economic effects are relevant to consider in formulating public policy; and second, it suggests that restricting parallel imports may have nonobvious, but nevertheless beneficial, effects on economic welfare.

Generally, a vertical restraint is a condition imposed by a firm operating at one level of an industry on a firm or firms operating at another level of the industry to govern the purchase, sale or resale of a product. Common types of vertical restraints are: resale price maintenance (RPM) - establishing the prices at which a distributor or retailer may sell a product; exclusive territories - limiting the geographic territory within with a distributor or retailer may sell a product; ${ }^{2}$ exclusive dealing preventing a firm from acting as the distributor or retailer for competing products;

2. It is also possible to place a limit on the type of customer that a distributor or retailer may serve; for example, amateurs vs. professionals or government vs. non-government. 
and typing - making the purchase of one product contingent upon the purchase of other goods and services. With the exception of RPM, vertical restraints do not involve the price of the product directly and are referred to collectively as nonprice vertical restraints. Since restricting parallel imports is akin to permitting manufacturers to establish exclusive territories in accordance with national boundaries, we will draw upon the extensive literature in law and economics on nonprice vertical restraints to understand the impact of parallel imports on manufacturers and consumers. See, for example, Comanor and Frech [1985], Katz [1989], Mathewson and Winter [1984 and 1986] and Rey and Tirole [1986].

U.S. law concerning nonprice vertical restraints has, after fluctuating considerably in the past, arrived at a stable, benign outlook on this issue. Nonprice vertical restraints, which produce vertical division of markets, have not been viewed harshly by the U.S. legal system when compared, for example, with RPM, which is per se illegal. ${ }^{3}$ Economists have made important contributions to competition policy in the U.S. by explaining the importance of the free-rider problem and its adverse impact on the incentive to invest in pre-sale and post-sale services. See, for example, Telser [1960 and 1990]. As a result, U.S. courts have moved from a predisposition toward limiting the control a manufacturer could exercise over its own distribution system to a case-by-case approach.

In Europe, EC commercial policy is biased strongly against practices which preserve the separateness of national markets - as restrictions on parallel imports surely do. However, nonprice vertical restraints, including exclusive territories, receive either a block exemption or an individualized rule of reason analysis at the hands of EC law.

\section{B. Gains from Restricting Parallel Imports}

\section{Pre-Sale Information and Post-Sale Service}

Some products by their nature are technically complex, infrequently purchased and hard to evaluate prior to purchase. Marketing such information-intensive or service-intensive products requires that potential consumers receive detailed infor-

3. The difference in the legal treatment of RPM and nonprice vertical restraints is troubling from an economic perspective given that the same basic economic analysis applies to both types of restraints. 
mation prior to purchase so that they can decide whether or not the product meets their needs. In addition, some products require service after purchase, such as advice on particular applications of the product or repair work under warranty. It is not always possible to charge potential customers separately for the pre-sale information or the post-sale services even though they are costly to provide. If providing information or service is essential to creating and maintaining the demand for the manufacturer's product, failure to do so will result in a decline in the demand for the product. In this case, the manufacturer of the product wants the information or service provided. Survival as a viable competitor depends crucially on the availability of essential information and service.

Restricting parallel trade in service-intensive or information-intensive products reduces the threat of free-riding and allows manufacturers to maintain control over decisions by distributors. Without the threat of parallel imports, the manufacturer of a product that is technically complex, infrequently purchased or hard to evaluate prior to purchase (quality-uncertain) can structure the distribution system for the product across countries so that the distributors in each country have the incentive to provide the essential information and service. The authorized distributors in a country are then able to capture the sales generated by their own investment in information and service. The manufacturer continues to sell its products in the country, distributors have an incentive to promote the products and to provide the essential information or service, and consumers have access to sufficient information about the product's features and to special services should the need arise.

Most pharmaceutical products are technically complex, infrequently purchased, especially for acute problems; and their effects on a particular patient cannot be observed until after the patient actually uses the product. Health care providers must receive information about new products, new indications for old products, or experience of other providers with particular products in order to provide highquality health care to consumers. New information is readily available in medical journals, at scientific meetings and from government agencies. However, because of its technical nature, this information is costly to transmit. Its inherent complexity means that successful dissemination requires predigestion, simplification and, often, explanation by teaching rather than mere reading. Without the provision of this information by direct mailings, advertisements in medical journals or direct contact by pharmaceutical representatives familiar with local medical practice, the pharmaceutical product will be underused or misused. Although less important, post-sale 
service - especially data gathering - is also necessary for the pharmaceutical manufacturer and, possibly, regulators. These data can be used to arrange for a health care provider to obtain a product on an expedited basis in, for example, experimental or emergency settings and to establish a link between the pharmaceutical manufacturer and health care provider for exchange of information about new research or ideas for research proposed by the health care provider. The distributor must also maintain detailed records about particular batches of a product and accept returns of products with expired shelf lives.

In order for a pharmaceutical distributor to furnish health care providers with the information that generates sales of a product and to monitor the experience of the product in a country, the distributor must have the proper incentive. Namely, the distributor must be allowed to make the sales of the product associated with its disseminating information about the product and monitoring reactions and product quality. If a parallel trader does not provide the information or service, but rather rides free on the authorized pharmaceutical distributor, the authorized distributor will eventually stop providing the information and service.

Parallel imports turn the provision of information and service by the manufacturer from marketing investments to superfluous costs. Consumers either use the products inappropriately or are actually deprived of efficient therapies. Sales of the product must fall.

The actual method and costs of providing information about pharmaceutical products may differ by country. Generally, contact occurs through some combination of announcements in medical journals, displays at scientific meetings, mailing of product specific information to health care providers, and direct person-to-person calls on health care providers. Pharmaceutical manufacturers often believe this last form of disseminating information - called detailing - is the most effective. It accounted for approximately 75 percent of promotional expenditures in 1989 . Representatives of a manufacturer or its distributor visit health care providers to describe the safety and efficacy of a product as well as information about contraindications, side effects and dosage forms.

Parallel imports will have adverse consequences whether the vertically integrated manufacturer or the distributor perform the function. The firm is merely a set of contracts between levels of production and, in an analytic sense, is no different from a contractual relationship governing the production and distribution of a product. Vertical integration does not alter the incentives of self-interested decision 
makers at the separate levels of the vertical chain. When independent parallel traders can purchase the product in a low-price country and resell it in a high-price country, thereby undercutting the local distribution network, even vertically integrated manufacturer/distributors can be discouraged from providing information and service. Research-based pharmaceutical firms usually have a sales force of detail representatives. Members of these marketing divisions contact physicians to inform them about products, but consumers obtain most pharmaceutical products from retail or hospital pharmacies. Pharmaceutical manufacturers rely on distributors or wholesalers mainly to provide service to these pharmacies. Caves, Whinston and Hurwitz [1991] conclude that "the increased role of independent wholesalers stems from computerization that allows specialist wholesalers to provide extensive services for pharmacies (including hospital pharmacies) that they supply exclusively" (p. 9).

Even if we assume that vertical integration through the detailing function allows the single country pharmaceutical manufacturer to internalize the information externality - that is, to invest in sales and service on its own behalf rather than relying on independent distributors - problems can still arise. Consider the case of Japan, which is the second largest pharmaceutical market in the world based on 1989 sales of $\$ 26.2$ billion. In Japan, 180,000 physicians prescribe and dispense pharmaceutical products. In order to disseminate information about products to these physicians, "foreign pharmaceutical firms must supplement their own sales forces with wholesalers' detailmen. An industry source states that successful competitors in the Japanese market provide intensive training to both the firm's sales personnel and wholesaler's sales staff." See ITC Report [1991], pp. 4-10. In addition, the process for gaining approval of a product for sale is biased in favor of Japanese firms. As a result, foreign firms will license a Japanese firm to distribute the product in Japan as a means of gaining access to the market.

In other countries, a pharmaceutical manufacturer may not have the flexibility to integrated vertically. For instance, a pharmaceutical manufacturer typically contracts for distribution of a product in countries where it does not have an adequate sales force to compete or its sales force does not have experience with a particular therapeutic class of products or segment (e.g., hospitals) of the health care industry. Typically, the manufacturer will grant an exclusive contract to the distributor. Parallel imports undermine the exclusivity. In other settings, national laws may require that a manufacturer employ a local distributor. The manufacturer must then provide the distributor with the incentive to provide essential information and 
service.

\section{Intrabrand vs. Interbrand Competition}

No matter what the regulatory regime or distribution arrangements, intrabrand competition has never been - nor could ever be - a strong force in the pharmaceutical industry. Intrabrand competition can increase efficiency only in industries within which a substantial proportion of total cost occurs at the distribution stage, such as where unique location factors lead to high distribution margins. In these cases, relaxing vertical restraints compels distributors (either independent or integrated) to reduce costs and margins because of competition from other distributors of the same product. In the pharmaceutical industry, distribution - apart from the provision of information and service - is a very small fraction of total cost. Consequently, the potential efficiency gains from artificially enhancing competition in the transportation of pharmaceuticals from manufacturers' warehouses to pharmacy shelves are limited.

It is feasible to view rules that prohibit manufacturers from preventing parallel imports within their distribution channels are regulatory requirements that introduce competition within the firm's organization. This also applies at other stages in the production process. Consider, for example, that manufacturers were prohibited from requiring plant managers to set the same internal, wholesale transfer price for products moving from the manufacturing to the distribution stage. That is, of course, tantamount to government-mandated competition at an upstream stage of manufacturing. In some settings, this may work; indeed, some firms are organized along principles of internal competition. But for other firms, the results could be disastrous. This arrangement creates strong incentives for plant managers to cut costs, and quality if need be, in order to ensure that their goods are given preference in the distribution system over the goods of competing plants. While the short-term effect may be lower prices to consumers, quality could suffer in the long term.

Restraints on intrabrand competition - in the form of parallel imports - will tend to enhance interbrand, therapeutic competition. Absent free riding, distributors can reap the full benefits of their market development efforts. They will efficiently promote their products in competition with other brands available in the country. Consumers benefit from competition in the form of the number of options available to treat a given problem at competitive prices.

As it stands now, brand loyalty and risk aversion create a strong tendency for 
health care providers to select products that experience suggests are effective, despite the presence in the market of therapeutically equivalent products at different, often lower, prices. Without an incentive to inform providers about alternatives with similar therapeutic properties, manufacturers lose sales and consumers (patients) fail to realize the benefits of competition. When pharmaceutical manufacturers are permitted to control the distribution of their own products, then distributors will have an incentive to promote these products through direct contact with health care providers. This activity requires extensive knowledge of local health care markets to understand the needs of patients, the prescribing tendencies of physicians, the inventory patterns of hospitals and pharmacies, and local regulatory schemes, and would not be undertaken without the expectation that the costs will be recovered in the form of increased sales.

\section{Distribution Costs and Product Quality}

Enhanced interbrand competition is not the only benefit from restricting parallel imports. Even without competing brands, restricting parallel imports can improve efficiency by reducing distribution costs. A product manufactured at a plant in high-price Country A and shipped to a low-price Country B will be a candidate for a parallel trader. The parallel trader will ship the product back to Country A. Not only will inefficiently high transportation costs be incurred, but there is an increased risk of damage or deterioration in quality due to excessive or improper handling.

Concerns about maintaining product quality are particularly relevant for pharmaceutical manufacturers and, ultimately, consumers. Many pharmaceutical products have special handling, labelling and storage requirements. It is difficult for the manufacturer and the consumer of a product sold by a parallel trader to know whether or not the product has been handled and stored properly. Moreover, the manufacturer bears the risk of legal liability or degraded reputation for the potentially serious consequences that could result from improper handling.

\section{Efficiency Losses from Restricting Parallel Imports}

The general outcome of restricting parallel imports is ambiguous - such a policy can be welfare enhancing or welfare diminishing. In this section, we focus on the anticompetitive effects of restricting parallel imports and assess whether or not these effects are likely to occur in the case of pharmaceutical products. 
There are three types of possible effects from restricting parallel imports that could result in restricted output. First, restricting parallel imports may facilitate collusion among either manufacturers or distributors. Second, restricting parallel imports may help to exclude potential rivals from a country. Third, once a policy regarding parallel imports is in place, it becomes difficult to change if technology improves or adverse consequences emerge. None of these, however, presents a problem for restricting parallel imports of pharmaceuticals.

The structural features of the pharmaceutical industry are lack of concentration, heterogeneous products, disparate competitive interests and attributes. They suggest that collusion at either the manufacturing or the distributing stage is unlikely even if restrictions against parallel imports enable firms to maintain control over the distribution of their products.

Restricting parallel imports raises the cost of entry into a country by competitors. However, in markets (or market segments) where there are relatively few barriers to entry, the potential for excluding rivals to the detriment of competition is limited. Absent a law restricting the number of distributors, the distribution stage of the pharmaceutical industry can be characterized as affording considerable freedom of entry. Manufacturers can enter by establishing their own distributorships. An independent distributor can enter by meeting regulatory and capital requirements. The latter requirements are not substantial and economies of scale are unlikely to exist. Even local firms find it possible to enter at the distribution level and to use this business as the platform to launch the development of a local industry.

National boundaries probably constitute the most economically sound geographic markets in regions of the world where such boundaries divide nations whose differences in pharmaceutical demand conditions and patterns of consumption exceed the differences within the nations themselves. The fundamental economic characteristics that generate distinct demand functions for pharmaceuticals include: income, age distribution of the population, prescribing patterns of health care providers, diet or other factors that influence health status, and consumer attitudes toward public versus private provision of health care. In addition, most often there is country-specific regulation of safety and efficacy; there are differences with respect to the products that can be sold in a country and the circumstances under which the products are used. There are also country-specific regulations regarding intellectual property protection and reimbursement of health care expenses. There may be government-provided health care, private insurance for health care ex- 
penses or some combination of government and private reimbursement. Other differences exist across countries with regard to cost containment efforts, product liability laws, tax laws, $R \& D$ incentives and export/import policies. As regions of the world such as the EC become unified for trading purposes, some of these factors may become less important. However, nation states are likely to remain the relevant geographic markets for pharmaceutical products and, as such, they represent the obvious units around which to organize an efficient distribution system.

\section{Monopsony}

International firms often sell products in markets governed by different institutional settings. In some settings, the prices are determined by the forces of supply and demand, but in others a government agency regulates the prices for certain products. Even when market systems govern the buying and selling of a given product, there may be differences attributable to a number of factors, including:

- local customs;

- market specific costs of production (e.g., transportation costs);

- whether the product is imported or produced domestically;

- number of buyers and other sellers;

- entry conditions; and

- public policy (e.g., taxes, antitrust, environmental controls).

Situations in which prices are set by governments differ based on the form and effectiveness of the price-setting process. In many countries, a national health service is a single buyer of health care products and services, including pharmaceuticals. Even when that is not strictly the case, governments often organize regulatory regimes so as to achieve a similar result - the government acting as price controller through the use of such devices as reference pricing, black-and-white lists or profit controls. These regimes correspond closely to the textbook situation of a single buyer in a market with many sellers - monopsony.

There are adverse welfare effects associated with the exercise of monopsony power. Just as a firm with monopoly power can raise prices above the competitive level and restrict output, a monopsonist is able to reduce prices below the competitive level and purchase less of a product than would be bought under competitive conditions. The monopsonist captures a portion of the producers' surplus. The sellers either accept the lower price or leave the market. In addition, resources that 
would be used to produce the product efficiently absent monopsony are shifted to other markets. The Merger Guidelines of Department of Justice (1984) state that "market power' also encompasses the ability of a single buyer or group of buyers to depress the price paid for a product to a level that is below the competitive price. The exercise of market power by buyers has wealth transfer and resource misallocation effects analogous to those associated with the exercise of market power by sellers."

Formally, for monopsony to be successful, three conditions are necessary. First, the buyer must control a large share of total purchases in a market. In the extreme case, the buyer controls all the purchases in a market. Second, there must be a direct relationship between the price of the product and the quantity supplied. That is, changing the quantity purchased of a product must have an effect on the price. Third, there must be barriers to entry into the buyers' market. If additional buyers can emerge quickly, purchases will expand and price and quantity will return to competitive levels as a result.

In an international setting in which a firm sells in some markets where monopsony power exists and others where it does not, parallel traders may obtain a product in the low-price (monopsony) country and resell the product in high-price countries (no monopsony). The parallel trade will displace sales in the high-price markets and provide a vehicle for extending the effects of monopsony power-lower prices, reduced quantities - beyond the single market. A major consequence of parallel imports from a country with a monopsony is that sales are diverted from final consumers in that country. The costs of serving the market are increased since the products purchased by the monopsonist find their way to other markets. The cumulative effect may be to force the seller to exit from the market with the monopsony. If so, final consumers in this market will lose all access to the product. Alternatively, when a firm chooses to remain in a low-price country with parallel trade, distortions in the location of production and in transportation will occur. Goods destined for domestic consumers will be transshipped to higher-price markets.

Pharmaceutical firms operate in many markets throughout the world where governments exercise monopsony power. The government may be on the only buyer of pharmaceuticals or may protect a single local distributor with laws prohibiting competition. Firms continue to sell in such settings since they are recovering their incremental cost or because they wish to generate goodwill. Pharmaceutical firms have no incentive, however, to devote $R \& D$ resources to 
developing products for a market with monopsony. If trade barriers fall, making parallel trade easier, parallel traders will divert products intended for distribution in the monopsony market to markets where prices are higher. Sales by the parallel trader will displace sales by the pharmaceutical firm in the high-price country. The firm's incentive to continue to sell in the monopsony market will be reduced, as it merely creates a low-cost source of supply for the parallel trader, resulting in competition for sales in other markets.

Pharmaceutical firms recover the costs of R\&D from sales of the successful products emerging from their $R \& D$ efforts. They must earn a return sufficient to continue investment in R\&D in order to develop new, improved products. Currently, there is a delicate balance between the cost and revenue streams. According to a study by Grabowski and Vernon [1990] of 100 New Chemical Entities (NCEs) introduced in the U.S. during the 1970 s, just 30 products earned a return greater than or equal to the average cost of R\&D for a NCE. If parallel trade from countries in which monopsony power drives prices below a competitive level displaces sales in other markets, the ability of the pharmaceutical firms to earn a return sufficient to cover the cost of R\&D is diminished. Fewer products will be profitable and manufacturers will devote fewer resources to R\&D in the long run. If, instead, parallel imports were restricted, the impact of monopsony power will be confined to the small pharmaceutical markets where it currently exists.

\section{Intellectual Property}

The traditional notion of competition that appears in economics textbooks is static price competition. There is, however, a dynamic form of competition that may be more important for welfare; namely competition through innovation. Firms rely on new, improved products to gain advantages over rivals and, ultimately, to contribute to social progress. The incentive for firms to devote resources to R\&D, the fuel for this type of competition, derives from the opportunity to gain an advantage over rivals and earn greater profits.

Most investment by firms in R\&D beyond basic research is irreversible. In addition, such investment is often product or process specific; thus, its benefits are not fungible. In the pharmaceutical industry, for example, the R\&D spending devoted to the clinical trials of a product is the most significant component of total R\&D spending. In clinical trials, the pharmaceutical firm examines the effects of a 
specific product in humans. Because the results of clinical trials cannot be used to obtain approval for a different product, these expenditures are sunk costs.

In order for firms to have the incentive to invest in R\&D activities, they must be able to retain the property rights to the output of the innovative process. Countries, therefore, have established mechanisms to protect the intellectual property resulting from the R\&D activities, including laws regarding patents, copyrights, trademarks and trade secrets. These intellectual property regimes offer varying degrees of protection for the output of R\&D. Some countries such as the U.S. have relatively strong systems for protecting intellectual property, while other countries, primarily developing countries, have relatively weak regimes.

The overall incentive to invest in $R \& D$ is directly related to the global strength of intellectual property protection available for the output of the innovative effort. Manufacturers' incentives to continue investing in R\&D depend upon substantial sales of products embodying technology protected by intellectual property laws in those countries with relatively strong regimes. Without such sales, manufacturers would not recover the costs of engaging in past R\&D and would, thus, be discouraged from making investments in the future. Furthermore, manufacturers often finance R\&D internally. Profits from sales of existing products are, therefore, essential to fund the development of new products.

Price differences among countries are related to the degree of intellectual property protection countries afford innovators. An effective patent system, for example, reflects a trade-off of higher prices in the present arising from the exclusivity granted to patentholders for the advantages of innovation through technical progress in the future. This connection is undermined, to some degree, by parallel trade. If parallel traders bring units of a product from the low-price country to the high-price country, the sales of the innovative firm will be reduced in the country with relatively strong intellectual property protection. The impact of parallel imports will be to increase the uncertainty that investment in R\&D will be recouped. This decreases the incentive to invest in R\&D and, ultimately, reduces the flow of new products for consumers in all markets.

Innovative firms are discouraged from distributing and selling their products in countries with weak intellectual property protection since these activities simply create a supply of low-price units of their products for parallel traders to exploit. Consumers in these low-price countries lose access to products and to the extent scale and learning economies exist, consumers in all countries pay higher prices 
once the global volume of sales is reduced. Less volume means higher costs and less experience.

In sum, parallel trade undermines the strength of the global intellectual property system. Parallel imports have adverse effects on firms' incentives to devote resources to $R \& D$, as well as the availability of the products from past innovative efforts for consumers in countries with poor protection of intellectual property. Reducing the incentives for parallel importing in R\&D-intensive industries such as the pharmaceutical industry, on the other hand, tends to preserve the price differences that exist across countries. As these price differences across countries are due partly to differences in intellectual property protection regimes, the incentive to devote resources to $R \& D$ is maintained.

\section{Conclusion}

We have analyzed the impact of parallel imports on manufacturers, distributors and consumers of pharmaceuticals. Our analysis applies to many industries; however, we believe that an industry-specific approach to developing a policy on parallel imports - such as the one we use here - is appropriate. We conclude that a public policy restricting parallel imports in pharmaceuticals has both immediate and longrun benefits in the form of improved welfare and enhanced prospects for innovation that are likely to offset any costs. These benefits are summarized below.

\section{A. Differential Pricing}

Differential pricing is ubiquitous in modern economies. There are settings within which differential pricing produces welfare gains. Pharmaceutical prices often differ across national boundaries due to variations in income, the age of the population, diet and medical practice patterns, as well as government regulation and cost containment efforts. Under these circumstances, restricting parallel imports in pharmaceuticals often yields the maximum benefits for producers and consumers alike. Despite the misleading term patent monopoly, a patented pharmaceutical product usually competes with other products in at least some uses. Without parallel trade, firms selling in several markets can use differential pricing to expand output. By so doing, they capture the benefits of scale and learning economies and reduce costs and prices overall. Moreover, the access to these scale economies may 
make it possible to introduce products into new geographic markets at lower prices, creating welfare gains that would otherwise go unrealized. The tendency towards a uniform price in the presence of parallel imports may encourage manufacturers to withhold a product from certain low-price countries, eliminating sales of the product in the low-price country and foregoing scale and learning effects. This will result in higher average prices in those countries in which the product is still available. These effects may be most significant in the emerging, capital-intensive biotechnology industry, where learning economies are particularly important. The willingness of small biotechnology companies to enter into joint venture global marketing agreements with multinational firms is evidence of the importance of expanding output to this segment of the industry.

\section{B. Control of Distribution}

Parallel importers may ride free on market development and quality control efforts of manufacturers and their authorized distributors, thereby, increasing risks to manufacturers and consumers, impeding entry into certain markets, raising the costs of distribution and reducing interbrand competition. Parallel importers, who neither disseminate information, provide service nor otherwise enhance a product, are able to sell the product because these functions are performed by local distributors whose economic viability is threatened by parallel imports.

Distributors of pharmaceuticals provide valuable sales and service efforts. They disseminate information to health care providers on the safety and efficacy of a product, account for returns of products with expired shelf lives, monitor experience with a product at the local level for adverse reactions and serve as a liaison between health care providers and research scientists. Consumer confusion arising from labelling problems and the introduction of counterfeit products through the parallel import channel are part of the pharmaceutical industry's recent history. Ultimately, these damaging effects may render the particular pharmaceutical product a less viable competitor with other therapeutically equivalent products.

\section{Monopsony}

Pharmaceutical firms often sell to monopsonistic national health services or private insurance schemes. Under these conditions, parallel trade, when combined 
with the beggar-thy-neighbor game by which governments attempt to reduce domestic pharmaceutical prices, foisting off $R \& D$ costs on others, tends to shift pharmaceutical manufacturing and R\&D to low-income, low-labor cost countries. This may lead to serious misallocation of resources. The low monopsony prices in one country offer an opportunity for parallel traders to extend the distortion created by monopsony to a neighboring country where a monopsony does not exist. Given that the overall returns to pharmaceutical $R \& D$ are dependent on a small number of profitable products, which are the likely targets for parallel importers, a policy that favors parallel trade to the detriment of these products will have a significant adverse impact on the incentive of pharmaceutical firms to continue investing in R\&D.

\section{Intellectual Property}

The adverse consequences of parallel imports may be most severe for firms that invest resources in $R \& D$ and rely on intellectual property laws to protect the output of that $R \& D$ effort. A patent is fundamentally a right to exclude others from a product or technique. Parallel trade can undermine an innovative firm's control ${ }^{4}$ over the distribution of its products to final consumers. If a distributor sells the product in a low-price country to a parallel importer, who ships the product into a high-price country in which the manufacturer already has a local distributor for the product, the reduction in profits reduces the incentive to continue investing in $R \& D$, which the intellectual property laws are intended to foster.

Parallel trade has undeniable political appeal. The attractiveness of the lower prices that parallel imports create, combined with the conviction that more trade is generally better than less trade, means that those who would restrict parallel trade are at a rhetorical disadvantage. In fact, the most accurate outlook on the problem is as an intellectual/industrial property issue; within this setting the trade-off between lower prices in the short run and long run efficiency gains is routinely evaluated.

4. Firms may lose control by various other means, for instance: (1) by deciding not to integrate the distribution portion of the vertical chain; (2) via local laws or customs that require the firm to distribute its products through a local distributor or to rely on local agents - such physicians and pharmacists in the case of pharmaceutical products - to prescribe and dispense their products; and (3) the exhaustion of intellectual property rights conveyed by a patent upon sale of the product to an independent distributor. 
We find that for the pharmaceutical industry, and probably for other similar ones, the short run price reductions parallel trade may yield are outweighed by its undermining both efficient distribution arrangements and patent protection.

\section{References}

Caves, R., M. Whinston and M. Hurwitz [1991], "Patent Expiration, Entry, and Competition in the U.S. Pharmaceutical Industry," Brookings Papers on Economic Activity-Microeconomics, Washington: Brookings Institution, pp. 1-66. Comanor, W. and H. Frech [1985], "The Competitive Effects of Vertical Arrangements?” American Economic Review 75: pp. 539-546.

DiMasi, J., R. Hansen, H. Grabowski and L. Lasagna [1991], "Cost of Innovation in the Pharmaceutical Industry,” Journal of Health Economics 10: pp. 107-142. Global Competitiveness of U.S. Advanced Technology Manufacturing Industries: Pharmaceuticals, Report to the Committee on Finance, United States Senate, on Investigation No. 332-302 under Section 332(g) of the Tariff Act of 1930, U.S. International Trade Commission, Publication 2437, September 1991 (ITC Report).

Grabowski, H. and J. Vernon [1990], "A New Look at the Returns and Risks to Pharmaceutical R\&D,” Management Science 16: pp. 804-882.

Hausman, J. and J. Mackie-Mason [1988], "Price Discrimination and Patent Policy," Rand Journal of Economics 19: pp. 253-265.

Katz, M. [1989], "Vertical Contractual Relations," Handbook of Industrial Organization I:edited by R. Schmalensee and R. Willig, Amsterdam: North Holland.

Mathewson, G. and R. Winter [1986], "Economics of Vertical Restraints in Distribution," in New Developments in the Analysis of Market Structure, edited by J. Stiglitz and G. Mathewson, Cambridge: MIT Press.

Mathewson, G. and R. Winter [1984], "An Economic Theory of Vertical Restraints," Rand Journal of Economics 15: pp. 27-38.

Merger Guidelines of the Department of Justice-1984, 49 Federal Register 26824, June 29, 1984.

Rey, P. and J. Tirole [1986], "The Logic of Vertical Restraints," American Economic Review 76: pp. 921-939. 
Schmalensee, R. [1981], "Output and Welfare Implications of Monopolistic ThirdDegree Price Discrimination,” American Economic Review 71: pp. 242-247. Telser, L. [1960], "Why Should Manufacturers Want Fair Trade?" Journal of Law and Economics 3:pp. 86-105

Telser, L. [1990], “Why Should Manufacturers Want Fair Trade II?” Journal of Law and Economics 33: pp. 409-417.

Varian, H. [1985], "Price Discrimination and Social Welfare," American Economic Review 75: pp. 870-875. 